\title{
COBERTURAS DE VACUNACIÓN ANTIGRIPAL EN EL PERSONAL SANITARIO: UNA LLAMADA A LA OPTIMIZACIÓN EN EL REGISTRO Y ANÁLISIS DE LOS DATOS
}

\author{
Guillermo Mena (1,2), Irma Casas $(1,2)$ y María Esteve $(1,2)$ \\ (1) Servicio de Medicina Preventiva. Hospital Universitari Germans Trias i Pujol. Badalona. España. \\ (2) Universitat Autònoma de Barcelona. Barcelona. España.
}

Los autores declaran que no existe ningún conflicto de interés.

\section{Señora Directora:}

La vacunación antigripal es la medida más efectiva de prevención frente a la gripe ${ }^{(1)}$. Su objetivo es reducir el impacto de la enfermedad en la comunidad en términos de mortalidad y $\operatorname{morbilidad}^{(2)}$. Entre los colectivos a los que se recomienda la vacunación antigripal estacional se encuentra el personal que trabaja en centros, servicios y establecimientos sanitarios, tanto de atención primaria como especializada $\mathrm{y}$ hospitalaria, sean públicos o privados ${ }^{(3)}$. El personal sanitario presenta mayor probabilidad de adquirir el virus, al estar en contacto con pacientes $\mathrm{y} / \mathrm{o}$ con material potencialmente infeccioso. Es importante destacar que el colectivo denominado "personal sanitario" engloba, por un lado, a personas cuyo trabajo, remunerado o no, se realiza en el ámbito de la atención sanitaria en contacto directo con pacientes o con material potencialmente infeccioso (médicos, enfermeros, auxiliares de enfermería, celadores, fisioterapeutas, terapeutas ocupacionales, personal técnico, de servicios dentales, farmacéuticos, de laboratorio, estudiantes y personal en capacitación, así como otro personal contratado por el centro sanitario). Por otro lado, también incluye a las demás personas que trabajan en estos centros y que, pese a tener un menor contacto con enfermos, están potencialmente expuestas a los mismos agentes infecciosos, independientemente de la relación administrativa de cada una de ellas con el centro sanitario (como pueden ser la gerencia

Correspondencia:

Guillermo Mena Pinilla

Hospital Universitario Germans Trias i Pujol

Ctra. de Canyet, $\mathrm{s} / \mathrm{n}$

08916 Badalona, España

guillemena.germanstrias@gencat.cat y el personal de oficina, servicio de cocina, limpieza, lavandería, seguridad, mantenimiento, personal administrativo y personal voluntario) $)^{(2)}$.

Tras el contacto con el virus, el personal sanitario infectado puede desarrollar complicaciones asociadas a la gripe, presentar un cuadro clínico de carácter leve, o simplemente permanecer asintomático. Independientemente de la clínica, la infección puede ser transmitida a los pacientes, a sus compañeros de trabajo y a los miembros de su família, suponiendo una mayor amenaza para aquellas personas que presentan más probabilidad de desarrollar complicaciones a causa del virus ${ }^{(1)}$. Sin embargo, la cobertura de vacunación de la gripe en el personal sanitario en España es habitualmente inferior al $35 \%{ }^{(4,5)}$, lo cual se considera un nivel subóptimo. El porcentaje de personal vacunado en otros países de Europa Occidental también presenta un amplio margen de mejora, como queda reflejado en la literatura, a través de una colección de estrategias dirigidas a promover la vacunación de la gripe año tras año entre el colectivo sanitario $^{(6)}$.

Al finalizar la temporada de vacunación antigripal, llega la evaluación de resultados mediante el cálculo de la cobertura de vacunación del personal que trabaja en los centros sanitarios. El cálculo obtenido, al dividir el número de trabajadores vacunados entre el número de trabajadores del centro, se convierte en una

\footnotetext{
Cita sugerida: Mena G, Casas I, Esteve M. Coberturas de vacunación antigripal en el personal sanitario: una llamada a la optimización en el registro y análisis de los datos. Rev Esp Salud Pública. 2020; 94: 25 de marzo e202003021.
} 
proporción cuyo uso con fines comparativos ha de emplearse con mucha cautela. El objetivo de esta carta fue, a través de los artículos de Tuells et $\mathrm{al}^{(7)} \mathrm{y}$ de Navalón et al ${ }^{(8)}$, analizar cuatro puntos que consideramos fundamentales a la hora de presentar las coberturas de vacunación antigripal en el personal sanitario:

i) Definición de las categorías profesionales incluidas en el denominador y, con ello, de si se trata de un estudio sobre todo el personal sanitario o bien solo sobre aquellas categorías que se exponen continuamente a pacientes. Las categorías que Tuells et $\mathrm{al}^{(7)}$ incluyeron en el análisis fueron las siguientes: médicos, enfermero/a, auxiliar enfermería, técnicos sanitarios, farmacéuticos, personal de apoyo, matronas, fisioterapeutas, nutricionistas, odontólogos, logopedas, optómetras, personal de documentación y psicólogos. Aunque en el objetivo del artículo los autores indicaban que se pretendía conocer las tasas de vacunación antigripal de las temporadas 2011-2012, 2012-2013 y 2013-2014 de todo el personal sanitario, el artículo presenta los datos de vacunación antigripal en trabajadores que se exponen directamente a pacientes. Por su parte, Navalón et al ${ }^{(8)}$ analizan las coberturas de personal sanitario incluyendo a trabajadores de la categoría de auxiliares administrativos, los cuales suelen tener contacto limitado con personas enfermas.

ii) Selección de la población a estudio. Tuells et $\mathrm{al}^{(7)}$ tomaron como población de referencia al personal adscrito contractualmente a fecha de 31 de marzo de 2014. Del total resultante, fueron identificados quienes disponían de una vinculación laboral en las tres campañas de vacunación antigripal a estudio. En el trabajo de Navalón et $\mathrm{al}^{(8)}$ también se incluyó a todo el personal adscrito contractualmente en los centros de atención primaria durante la temporada de vacunación a estudio. Se trata de dos ejemplos de selección de toda la población expuesta durante el período a estudio. Otros estudios, como el de Llupià et al ${ }^{(9)}$ tomaron como referencia una $\mathrm{n}$ poblacional aproximada, en este caso a través del número de trabajadores temporales y permanentes de un día a mediados del mes con más actividad de vacunación (noviembre en 2007 y octubre en 2008).

iii) Mejora en la precisión del personal incluido en el numerador, incluyendo también a los trabajadores vacunados de la gripe en otros centros sanitarios. Los artículos de Tuells et $\mathrm{al}^{(7)}$ y Navalón et $\mathrm{al}^{(8)}$ analizaron ambos la vacunación en centros sanitarios de la Comunidad Valenciana. En dicha región existe el Registro Vacunal Nominal (RVN) de la Conselleria de Sanidad de la Generalitat Valenciana ${ }^{(10)}$. El RVN es un portal que almacena la información relativa a las vacunas administradas a cada persona de forma individual en la comunidad. Una de las muchas ventajas de disponer de registros autonómicos como el RVN es que permiten conocer si el trabajador contratado en un centro sanitario ha recibido la vacuna de la gripe en otro punto de vacunación de la misma comunidad autónoma.

iv) Análisis de coberturas de vacunación en subgrupos. Habitualmente, el análisis se presenta por categoría laboral y/o por servicio o departamento. Sin embargo, consideramos que debe ponerse especial atención a la cobertura de vacunación antigripal en aquellos trabajadores que desarrollan la actividad asistencial con pacientes especialmente vulnerables y en aquellos que presentan más riesgo de ser infectados (mayor exposición laboral a la gripe), así como en el personal que presentan mayor probabilidad de complicaciones por el virus de la gripe (aquellos pertenecientes a algún grupo de riesgo).

Los servicios y/o categorías con mayor exposición laboral a la gripe pueden variar entre los diferentes centros. Un ejemplo de cómo se podría medir dicha exposición es el presentado en el trabajo de Tuells et $\mathrm{al}^{(7)}$ : previamente a la 
campaña de vacunación 2013-2014, se contabilizaron las solicitudes de detección de virus de la gripe cursadas por servicio en relación a pacientes con sospecha clínica.

La vacunación del personal sanitario es, además de una estrategia de protección indirecta de la población especialmente vulnerable, una medida de protección individual, sobre todo en casos de trabajadores con mayor riesgo de gripe grave o con patologías susceptibles de agravarse por gripe. Las reticencias que puede presentar un sanitario perteneciente a algún otro grupo de riesgo han de ser estudiadas. Para ello, sería conveniente no solo calcular la cobertura en dichos subgrupos de sanitarios con factores de riesgo, sino también planificar y, posteriormente, evaluar estrategias de promoción dirigidas a los $\operatorname{mismos}^{(11,12)}$.

La introducción de información relativa a las vacunas administradas en los registros autonómicos, como el RVN de la Generalitat Valenciana, así como la utilización de las plantillas de trabajadores con vinculación contractual durante toda la temporada de vacunación antigripal, permiten conseguir coberturas de vacunación antigripal más precisas. Para el diseño de estrategias de promoción de la vacuna antigripal dirigidas al personal sanitario que asiste a pacientes especialmente vulnerables frente a la gripe, así como a aquellos con mayor exposición laboral a la gripe y para los que presentan mayor probabilidad de desarrollar complicaciones por este virus, puede ser de utilidad el análisis de coberturas por subgrupos.

\section{BIBLIOGRAFÍA}

1. Ministerio de Sanidad, Consumo y Bienestar Social. Preguntas y Respuestas sobre la vacunación frente a la gripe (profesionales sanitarios) ¡Vacúnate!, ¡Protégete y Protege a tus pacientes! Disponible en: https://www. mscbs.gob.es/profesionales/saludPublica/prevPromocion/ vacunaciones/docs/Preguntas_respuestas_gripe_profsanitarios_2019-2020.pdf.

2. Grupo de trabajo vacunación en población adulta y grupos de riesgo de la Ponencia de Programa y Registro de Vacunaciones. Vacunación en grupos de riesgo de todas las edades y en determinadas situaciones. Comisión de Salud Pública del Consejo Interterritorial del Sistema Nacional de Salud. Ministerio de Sanidad, Consumo y Bienestar Social, Julio 2018. Disponible en: https://www.mscbs. gob.es/profesionales/saludPublica/prevPromocion/vacunaciones/VacGruposRiesgo/docs/VacGruposRiesgo_todas_las_edades.pdf.

3. Consejo Interterritorial. Sistema Nacional de Salud. Recomendaciones de vacunación frente a la gripe. Temporada 2019-2020. Disponible en: https://www.mscbs. gob.es/profesionales/saludPublica/prevPromocion/vacunaciones/docs/Recomendaciones_vacunacion_gripe.pdf.

4. Ministerio de Sanidad, Consumo y Bienestar Social. Tabla 13. Coberturas de vacunación frente a gripe en $\geq 65$ años, personas de 60-64 años, embarazadas y personal sanitario. Comunidades autónomas. Campaña 2018-2019 (actualización). Secretaría general de sanidad. Dirección General de Salud Pública e Innovación. Subdirección General de Promoción de la Salud y Vigilancia en Salud Pública. Disponible en: https://www.mscbs.gob.es/profesionales/saludPublica/prevPromocion/vacunaciones/docs/ CoberturasVacunacion/Tabla13.pdf.

5. Ministerio de Sanidad, Consumo y Bienestar Social. Histórico de coberturas de vacunación. Disponible en: https://www.mscbs.gob.es/profesionales/saludPublica/prevPromocion/vacunaciones/HistoricoCoberturas.htm.

6. Dini G, Toletone A, Sticchi L, Orsi A, Bragazzi NL, Durando P. Influenza vaccination in healthcare workers: A comprehensive critical appraisal of the literature. Hum Vaccin Immunother. 2018;14(3):772-789. 
7. Tuells J, García-Román V, Duro-Torrijos JL. [Influenza vaccination coverage (2011-2014) in healthcare workers from two health departments of the Valencian Community and hospital services more vulnerable to the flu.]. Rev Esp Salud Publica. 2018;92.

8. Navalón-Ramon E, Martínez-Pardo I, Sendra-Barbosa T, Hernández-Ferrando N, Morcillo-Escudero B, EsquerHernandis V. [Use of mobile immunization teams to increase influenza vaccination coverage among heatlthcare workers. A community intervention trial]. Rev Esp Salud Publica. 2019;93.

9. Llupià A, García-Basteiro AL, Olivé V, Costas L, Ríos $\mathrm{J}$, Quesada $\mathrm{S}$ et al. New interventions to increase influenza vaccination rates in health care workers. Am J Infect Control. 2010;38:476-81.
10. Registro de Vacunas Nominal de la Conselleria de Sanitat. Dirección General de Salud Pública. Disponible en: https://rvn.sp.san.gva.es/portalSIV/LoginServlet.

11. Ministerio de Sanidad, Consumo y Bienestar Social. Conocimientos, actitudes y prácticas de la vacunación frente a la gripe. Disponible en: https://www.mscbs.gob.es/ profesionales/saludPublica/prevPromocion/vacunaciones/ Conocimientos_actitudes_practicas_GRIPE.htm.

12. Grupo de trabajo de vacunación frente a la gripe. Ministerio de Sanidad, Consumo y Bienestar Social. Disponible en: https://www.mscbs.gob.es/profesionales/ saludPublica/prevPromocion/vacunaciones/Ponencia.htm. 